\title{
Anorexia, a First Sign of Diagnosis in Severe Pediatric Disorders
}

\author{
RAMONA-MIHAELA NEDELCUTA ${ }^{1 *}$, GIGI CALIN ${ }^{1}$, VLAD DUMITRU BALEANU2*, DRAGOS VIRGIL DAVITOIU ${ }^{3 *}$, \\ DANIEL-IULIAN VOICULESCU4", CECIL SORIN MIREA ${ }^{5}$, TIBERIU STEFANITA TENEA COJ AN ${ }^{6}$, BOGDAN SOCEA7, \\ DRAGOS OVIDIU ALEXANDRU ${ }^{8}$, DIANA CLENCIUㅇ, VICTOR GHEORMAN ${ }^{10 \#}$, ION UDRISTOIU10\#, VERONICA CALBOREAN ${ }^{11 \#,}$ \\ COSMIN ALEXANDRU CIORA ${ }^{12}$ \\ IUniversity of Medicine and Pharmacy of Craiova, Pediatrics Department, 2 Petru Rares Str., 200349, Craiova, Romania \\ 2University of Medicine and Pharmacy of Craiova, Surgery Department, Clinical Emergency Hospital Sf. Pantelimon Bucharest, \\ 340-343 Pantelimon Road, 021659, Bucharest, Romania \\ ${ }^{3}$ University of Medicine and Pharmacy of Bucharest, Surgery Department, Clinical Emergency Hospital Sf. Pantelimon Bucharest, \\ 340-343 Pantelimon Road, 021659, Bucharest, Romania \\ ${ }^{4}$ University of Medicine and Pharmacy Carol Davila Bucharest, Department of Surgery Universitary Emergency Hospital Bucharest, \\ 169 Splaiul Indepenei, 050098, Bucharest, Romania \\ EUniversity of Medicine and Pharmacy of Craiova, Surgery Department, 2 Petru Rares Str., 200349, Craiova, Romania \\ שUniversity of Medicine and Pharmacy of Craiova, Department of Surgery, CFR Hospital of Craiova, Stirbei-Voda Str., 200374,Craiova, \\ Romania \\ ${ }^{7}$ General Surgery Clinic, Emergency Clinical Hospital Sfantul Pantelimon, 340-342 Pantelimon Road, 021659, Bucharest, Romania \\ 8University of Medicine and Pharmacy of Craiova, Department of Medical Informatics and Biostatistics, 661 Mai Blvd, 200638, \\ Craiova Romania \\ 9. University of Medicine and Pharmacy of Craiova, Department of Metabolism and Nutrition Diseases, Filantropia Clinical \\ Hospital of Craiova, 1 Filantropiei Str., 200143, Craiova, Romania \\ 10. University of Medicine and Pharmacy of Craiova, Psychiatry Department, Neuropsychiatry Hospital of Craiova, 24 Potelu \\ Alley, 200473, Craiova, Romania \\ 11. University of Medicine and Pharmacy of Craiova, Cardiology Department, 2 Petru Rares Str., 200349, Craiova, Romania \\ 12. Carol Davila University of Medicine and Pharmacy, Discipline of Gastroenterology and Hepatology, 8 Eroii Revolutiei Blvd., \\ 050474, Bucharest, Romania
}

\begin{abstract}
Anorexia, as a symptom, is part of the complex picture of a large pediatric pathology. Through attentive observation, anorexia as a single sign, may announce the onset of serious and particular affections. In all 4 cases, anorexia was a singular sign for a period of time before the complete illness was established. Whether adenoid cyst, cerebral abscess, pontocerebellar atrophy, Wilms tumor, neuroendocrine system of hunger regulation, satiety, complex control achieved through interactions of the limbic-hypothalamus-cortex system, come into operation with the occurrence of organic anorexia, different of the psychogenic anorexia (usually common in adolescents). The study is an alarm signal on the importance of a symptom in early diagnosis, and the rapid establishment of therapy in severe life threatening conditions.
\end{abstract}

Key words: anorexia, symptom, diagnosis

Anorexia is an eating disorder with physical and emotional implications for the patient. Moreover, it can be considered a lethal psychiatric disorder with on increased risk of death (4 times higher than in major depression - in a study on adults.) Practically, that morbid condition is characterized by the loss of desire or appetite, which occurs as a symptom in the course of general illness or as a longlasting behavior in the presence of psychomotor or neuroendocrine disorders [1,2].

Hunger and satiety are part of a complex system of behavioral regulation and integration involving the hormonal system (leptin, ghrelin, insulin and cholecystokinin contributing in slowing gastric evacuation), nervous regulation by hypothalamus and limbic system and involves neuropeptides, glycemic homeostasis and other factors ex TNF $\alpha$ with anorexic role - glucagon like peptide GLP1[3].

Anorexia nervosa is a rarer entity in pediatric pathology, rather than in adults, especially in adolescents[4].

Possible causes

Newborn -NS (nervous system) disease, birth defects, meningo-cerebral haemorrhage, congenital bucopharyngeal malformations, cardiovascular disorders, metabolic diseases.
Infant - Iron and vitamin C deficiency, chronic digestive diseases, meningo-cerebral sequelae, encephalopathies, oral antibiotics, sulphamides, vitamin D intoxication, food and care mistakes, overuse, conflicting situations, affective frustrations, infections, genetic factors are involved in a unsolved proportion.

Causality diagnosis is extremely difficult, laborious, often a diagnosis of exclusion. There are rare diseases found in current pediatric practice that may have as anorexic onset.

\section{Experimental part}

Material and method

4 cases where anorexia was the only sign of onset of the condition

Case I-0.I. 2 years old of cerebral abscess

Case II -G.V. 5 years old adenoid cyst

Case III -V.N. 6 years old PCH2 (pontocerebellar hypoplasia) syndrome

Case IV -P.K. 3,6 years old years Wilms' tumor

Case I. A 2-year-old patient (coming from a family with religious and food taboos) has a serious overall condition, anorexia for about 2 weeks, dehydration, sporadic vomiting and diarrheal stools at home, conscious, temporospatial disorientation.

\footnotetext{
*email: baleanuvlad@gmail.com; Phone: 0040765865886

\# The authors contributed equally to the manuscript and share first authorship 
The patient presented 1 year and 3 months ago, 2 moments of temporary loss of consciousness, of unspecified duration, accompanied by muscle contraction, and in the last 3 months there was a regression in neuromotor function.

Clinical - poor nutritional condition, diminished adipose tissue, cutaneous and mucosal pallor, slow skin turgor response, tachycardia cardiac sounds, $\mathrm{AV}=120$ beats per minute, systolic murmur II (functional due to severe anemia), dyspnea sine materia, $\mathrm{FR}=50 \mathrm{resp} / \mathrm{min}$., without evidence pulmonary manifestations, excavated abdomen, diarrhea stools, spontaneous urination, rare, without stiff neck, neuromotor retard.

Hydroelectrolytic rebalancing treatment with low rhythm has been established in order not to worsen functional cardiac failure, oxygen therapy, antibiotherapy, antidiarrheal therapy.

At $2 \mathrm{~h}$ after admission there was an irreversible cardiorespiratory stop and death.

The anatomopathological diagnosis is:

1. Right hemisphere cerebral abscess

2. Protein-calorie malnutrition

3. Heart failure

4. severe anemia

5. epilepsy

6. severe psychomotor retardation

7. neglected child-social case

Case I - Cerebral abscess multiple causes -explanations

1. somatic impairment of cerebral structures / disorganisation $1 / 2$ left hemisphere

2. alteration of the limbic system

3. severe retardation, mastication disorder, swallowing

4. Infectious systemic impregnation that acts as a thief calories

5. Persistent / vegetarian food taboos level

6. neglecting closely with the family socio-economic

case II - rahnoidian cyst

Case II

A 5-year-old patient with severe anorexia. The clinical examination is normal, the laboratory tests are in normal parameters for the child's age, but the anamnesis reveals a c by bicycle fall 5 months ago. After CCT, the child did not experience loss of consciousness, headache or vomiting. The imaging examination specified the diagnosis of arachnoid cyst with dimensions $4.5 / 5.5 \mathrm{~cm}$ without associated lesions localized left fronto-tempoparietal cerebral cortex. 2 months after surgery, CT scan releaves an anterior temporal mass and 10 months postoperatively the dimensions exceed the previous ones to $5.5 / 6.9 \mathrm{~cm}$, with cyst-like appearance inserted in the Sylvian fissure with minimal neighborhood affection on left cerebral artery.

At 5 years post intervention, the cyst has 6.5/4.5/7.6 with left tempoparietal localization with effect on the frontal lobes, left tempoparietal inserted at the Sylvian fissure with its deformation, as well as deformation of the skull, ventricular dilation, cortical gliolysis and areas of atrophy in the left fronto-tempoparietal cortex (fig. 1,2).

Atrophy has become severe, with the metabolic status of the patient being altered.

It also associates other diagnoses: severe anorexia, hypotrophy, secondary anemic syndrome, iatrogenic epilepsy, spasmophilia, impaired seizures, transient neurologic deficit, recurring cyst.

In this case the causes of anorexia are:

Cyst compression on the neighboring structures causes stimulation on limbic, paralimbic structures involved in the regulation of hunger and satiety [5].

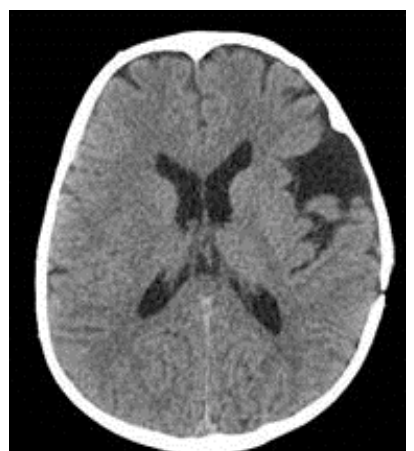

Fig. 1. CT scan 10 months after surgery

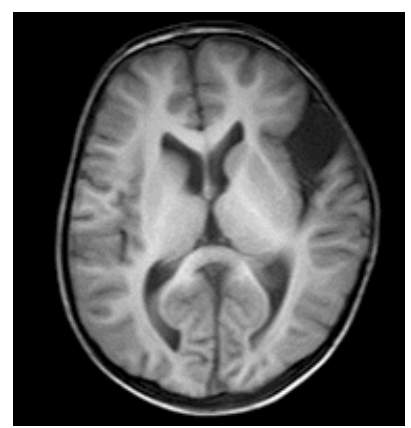

Fig. 2. MRI after 5 years
The post-intervention of evacuation of the liquid content, the evolution was initially favorable, with an interval of 3-4 months, seusequantly, the fluid accumulation broughtback the initial anorexic symptoms, accentuated and punctuated by several symptoms: epilepsy, transient paresis, affective crises.

Contrary the cases presented in the literature where surgery is performed when the picture of the disease is as complex as possible, after the onset of neurological deficit or epileptic seizures, in this case, the somatoneurological disorder was accelerated post-surgery.

\section{Case III}

6-month-old baby with normal weight $=3500 \mathrm{~g}$, Apgar 8 , caesarean delivery, has approximately 5 weeks of anorexia that is accentuated in time.

At the clinical examination is found malnutrition with current w eight $=170 \mathrm{~g}$, anemic syndrome associated with psychomotor retardation (does not respond to visual stimuli, sounds, does not catch objects, does not sit, has difficulty in supporting the head).

A gay diet is set up, the child not having a correct coordination of the act of swallowing, and sending evidence for the genetic analysis of the karyotype of both parents and the child. The results showed severe chromosomal abnormalities in parents and children: interstitial duplication of the short $Y$ chromosome arm, interest in the p22-12 region (in both parents), interstitial deletion of the long arm of chromosome 11 (to father), interstitial deletion of the short arm of chromosome 12, in the region p12.21 (to father), an interstitial duplication of the short arm of chromosome 1 in the region p36-32 (to the mother). The child has three mutations: an interstitial duplication of the short arm of the Y, the region p22.12 (as in both parents), an interstitial deletion of the long arm of $\mathrm{cr} 11$, which interests the region q 24.2 (also present to father), and an interstitial deletion of the long arm of chromosome11, in q 24.2 region (also present to the father), and an interstitial deletion of the short arm of chromosome 12 that interests the region p11.21 (also present to dad).

The diagnosis of $\mathrm{PCH} 2$ has been established.

Pontocerebellar atrophy directly affects the process of muscular coordination involved in the act of nutrition (mastication, swallowing), seizure, and aggravation of the retardation over time. The clinical aspect is inconsistent with survival.

Over time, severe anorexia has been associated with other diagnoses. At 1 year, the child presents severe malnutrition, severe anemic syndrome, epilepsy, severe anorexia. Severely psychomotor retard. At 1.2 years, the patient died.

Anorexia's explanation associated with severe chromosomal abnormality results in direct damage to 
muscle tone coordination, muscle atrophy and secondary malnutrition as immediate consequence.

The occurrence of paroxysmal convulsive disruptions aggravates psychomotor retardation, causes secondary cerebral atrophy, affects the superior integrative control that cerebral cortex has in the nutrition process.

Involvement of mastication and swallowing acts by cerebellum stimuli is completely impaired, the act of nutrition being disorganized (fig. 3).
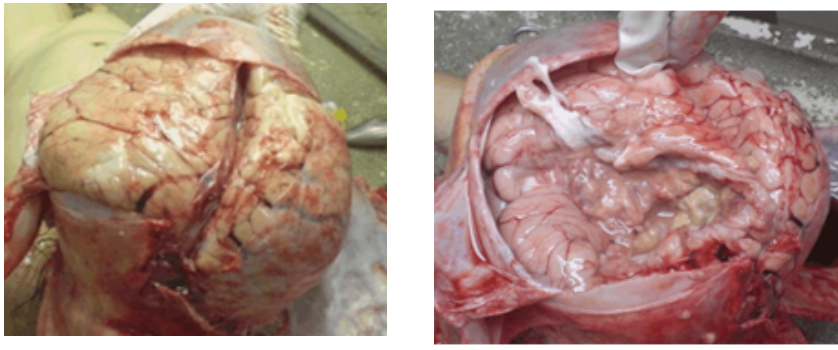

Fig. 3 Macroscopic aspects: swelling of the left cerebral hemisphere (left), and diffuse cerebral tissue as wall (right)

Case III -PCH2 - explanations

Pontocerebellar atrophy directly affects the process of muscular coordination involved in the act of nutrition (mastication, swallowing), seizure, and aggravation of the retardation over time. The clinical picture is inconsistent with survival (fig. 4).

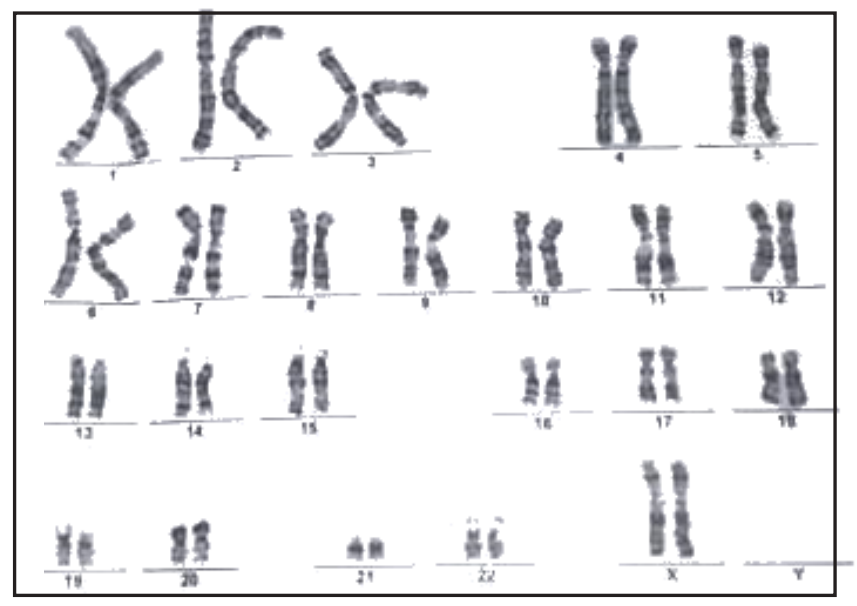

Case IV

Fig 4 Karyotype

A 3,6 years old pacient with anorexia for approximately 2 weeks, with $900 \mathrm{~g}$ weight loss in this period $(12.7 \mathrm{~kg})$.

The medical exam does not bring pathological data. The laboratory test shows a slight increase in the nonspecific parameters associated with inflammation (ESR, PCR, fibrinogen).

The abdominal echography shows the presence of a mass of approximately $4.3 / 3.4$, in the upper pole of the left kidney, nonhomogeneous echographic appearance with areas of tissue necrosis that does not exceed the renal capsule but compresses the renal sinus, the diagnosis being established as Wilms tumor, diagnosis subsequently confirmed postoperatively, both macroscopically, microscopically and by immunohistochemistry [6]. The patient followed the full oncologic treatment protocol postsurgery, being declared cured at 3 years post-intervention [7]. Anorexia persisted and increased during the chemotherapy series, currently 5 years after the intervention, the child being completely recovered somatic, nutritional, neuropsychic (fig. 5).

Case V - Wilms' tumor - explanations

1. Impregnation caused by oncological affection causes increased catabolism 
The limbic system, in its entirety, is an interwoven region between the external environment and the internal world. It powers the upper areas of the cerebral cortex and the instinctive parts of the nervous system of the trunk and the marrow as well as the autonomous NS. The hippocampus, due to the multitude of information received, can achieve a synthesis and influence of the hypothalamus, with multiple implications in somatovisceral functions [10].

The frontal lobe is the highest level of autonomous function integration.

Experiences on it (damage / stimulation) cause changes in bladder, intestinal, temperature and sweat control.

The hunger center is made up of neurons that form the ventrolateral nuclei of the hypothalamus. Stimulation is done at the homeostatic level of hypoglycemia, destruction causes anorexia. The center of satiety is located in the ventromedial nucleus of the hypothalamus. Stimulation is achieved by fatty acid hyperglycemia [11].

The studies on the mechanism of reflex regulation of food intake are incomplete because a multitude of chemical stimuli (olfactory, taste), homeostatics (sugar, lipid, enzyme, protein) act synergistically on the hunger center (fig. 7).

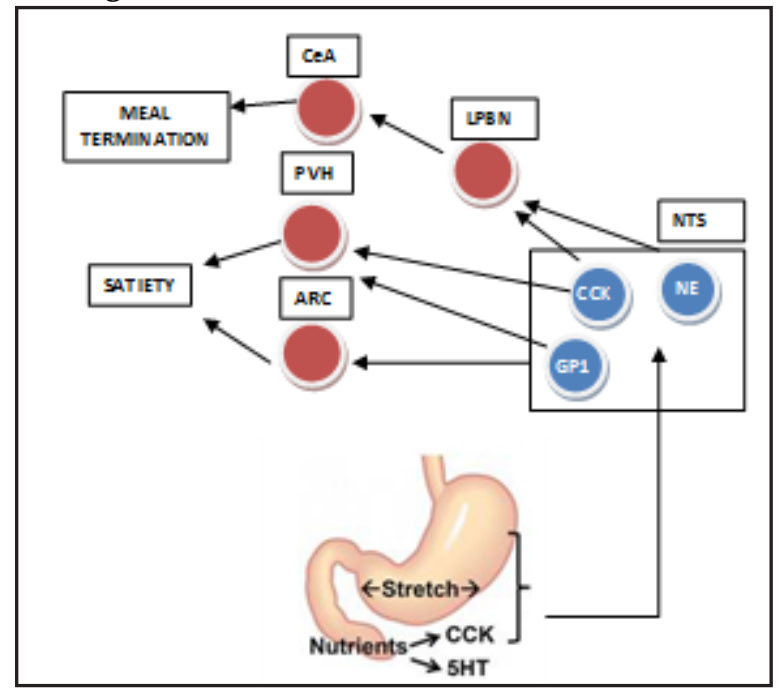

Fig. 7 Satiety

NTS neurons activate LPBN neurons, and this promotes meal termination via projections to the central amygdala (CeA) . NTS neurons also project to the PVH, where they promote satiety. NTS neurons can promote satiety, perhaps via their projections to the PVH and ARC.

CCK = cholecystokinin GLP-1=glucagon-like peptide 1 $\mathrm{NE}=$ endogenous norepinephrine NTS=nucleus of the solitary tract LPBN= lateral parabrachial nucleus CeA = central amygdala $\mathrm{PVH}=$ paraventricular hypothalamic nucleus $A R C=$ hypothalamic arcuate nucleus.

Efferent pituitary impulses have an effect on intestinal contractility, blood irrigation, with multiple influences on ingestible feeding behavior, both under the command of the cerebral cortex (fig. 8).

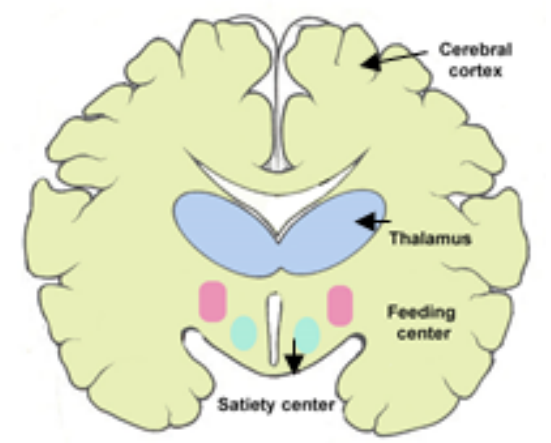

Fig. 8 The feeding center
In practice, an emotional component, an instinctual one, another learns through various associations, involving the multiple structures (cortex, hypothalamus, limbic system, tonsils) that contain a vast reactive inheritance underlying the act of nutrition. The starting point is profound at the level of organogenesis and ends at the behavioral level through the development of feeding rituals based on mechanisms of knowledge. The hypothalamus is the one that will achieve the neuropsychic level of superior adaptive integration [12-18] (fig. 9).

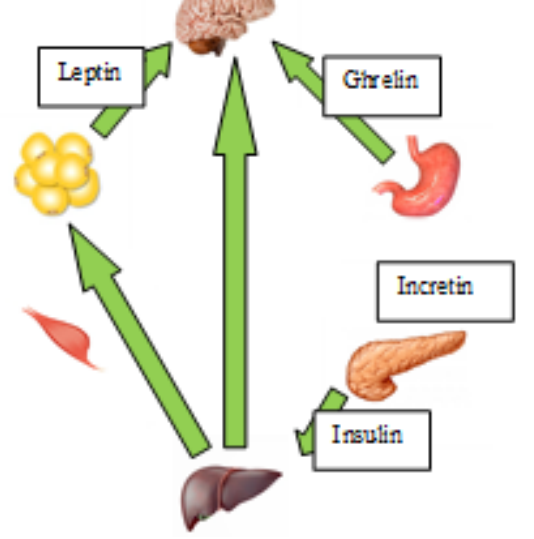

Fig. 9 Appetite and hunger

Child anorexia is an onset symptom that may indicate a severe affection. Even singular, in the initial form of debut, we must give this important sign, without being minimized.

Investigations should be complex and in-depth, starting with thorough medical history, complete clinical examination, laboratory, imaging, genetic or immunohistochemistry tests. It is a complete protocol that eliminates possible artefacts that would delay a correct diagnosis and the application of the curative treatment potential.

We are in era of developing and influencing aberrant eating behaviors, an era in which psychogenic anorexia, especially in adolescence, but also in school or preschool children, including those deprived of parental affection, is experiencing an unprecedented boom.

The path of clinician thinking may be experiencing multiple traps, and relying on stereotypes, pastexperiences, is and can be extremely damaging [19-26].

After removing the banal medical / digestive diseases, cancers, chronic inflammation, anosmia, loss of taste, known cerebral diseases, depression, anxiety, medication (amphetamines, antibiotics, antiinflammatory etc.) or bad eating habits, we must thoroughly investigate this cardinal signal of the body to diagnose / exclude a possible rare disorder of pediatric pathology.

\section{Conclusions}

The complexity of anatomical, nervous, hormonal, homeostatic, behavioral, mental relationships makes anorexia an extremely extensive chapter in ongoing research.

This paper is an alarm signal that shows the importance of complete investigation from sign / symptom to anamnesis and correct diagnosis.

\section{References}

1.NEDELCUTA R., POPESCU M., CALIN G., Digestive Manifestations in Wilms' Tumor, Proceeding of the Neurogastro 2017 - meeting of the Romanian Society of Neurogastroenterology with Rome IV Regional Central East European Meeting, (lasi, Romania, 16-18 March 2017, pg 200-204, ISBN 978-88-95922-89-8.

2.BRYANT-WAUGH R. Overview of eating disorders. In: B Lask, R Bryant-Waugh (eds). Anorexia Nervosa and Related Eating Disorders 
in Childhood and Adolescence. Hove: Psychology Press; 2000. pp. $27-$ 40.

3.TOLHURST G, REIMANN F, GRIBBLE FM. Nutritional regulation of glucagon-like peptide-1 secretion. J Physiol. 2009;587(1):27-32

4.JAKOB BIRAN, MAAYAN TAHOR, EINAV WIRCER, AND GIL LEVKOWITZ, Role of developmental factors in hypothalamic function, Front Neuroanat. 2015; 9: 47.

5.MAZURKIEWICZ-BEfDZIÑSKA M1, DILLING-OSTROWSKA E., Presentation of intracranial arachnoid cysts in children: correlation between localization and clinical symptoms. Med Sci Monit. 2002 Jun;8(6):CR462-5.

6.GOMMERSALL LM, ARYA M, MUSHTAQ I, DUFFY P, Current challenges in Wilms' tumor management, Nat Clin Pract Oncol 2, 2006: 298-304 7.GURNEY JG, BONDY ML: Epidemiology of childhood cancer; in Pizzo PA, Poplack DG (eds): Principles and Practice of Pediatric Oncology, ed 5. Philadelphia, Lippincott Williams \& Wilkins, 2006, pp $1-13$.

8.KALRA SP, DUBE MG, PU S, XU B, HORVATH TL, KALRA PS. Interacting appetite-regulating pathways in the hypothalamic regulation of body weight. Endocrine Rev 1999;20: 68-100.

9.PATINO LD, YUDCHAK CG, BARBIERI DP, STRAMESI J M, CHAMPAGNE VAND RAMUNDO MP, Comparative Study on the Effectiveness Between Intensive Outpatient Care and Partial Hospitalization Treatments in Patients Diagnosed with Eating Disorders, Archives of medicine, 2018, Vol.10 No.1:9, 1-11

10.SCHWARTZ MW, WOODS SG, PORTE D JR., SEELEY RJ, BASKIN DG. Central nervous system control of food intake. Nature 2000;404:66171.

11.SWEENEY P, YANG Y. Neural circuit mechanisms underlying emotional regulation of homeostatic feeding. Trends Endocrinol Metab. 2017;28:437-448

12.WATERSON MJ, HORVATH TL. Neuronal regulation of energy homeostasis: Beyond the hypothalamus and feeding. Cell Metab. 2015;22:962-970

13.BALEANU, V.D., CONSTANTIN, D.V., PASCAL, A. , ALEXANDRU, D.O., BOBIC, S., SOCEA, B., MANDA, A.L., DAVITOIU, D., DIJ MARESCU, A.L, GEORGESCU, I., MIREA, C.S., Use of Synthetic Protetic Materials in Surgical Abdominal Defects Analysis of the Advantages and Lack of the Liechtenstein Method. Rev.Chim. (Bucharest), 69, no. 7, 2018, p. 1740-3.

14.CALBOREAN, V., GHEORMAN, V., OCTAVIAN, I., MUSTAFA, R.E.,COJOCARU, P.A., ALEXANDRU, D.O., GALCEAVA, O., MITA, A.,MISCOCI, S.A., AL NAMAT, R., GHEONEA,D.I. QT interval analysis in patients with chronic liver disease, Rev. Chim. (Bucharest), 69, no. 5, 2018, p.1134-1138.

15. CALBOREAN, V., CIOBANU, D., MIREA, S.C., GALCEAVA, O.,GHEORMAN, V., PADUREANU, V., FORTOFOIU, C.M., FORTOFOIU,M., MITA, A., DINESCU, S.N., MISCOCI, S.A., DINESCU, V.C. Benefit of Cardiac Resynchronization Therapy in Patients with Heart Failure. Rev. Chim. (Bucharest), 69, no. 9, 2018, p.2461-2464.
16. CALBOREAN, V., MISCOCI, S. A., ISTRATOAIE, O., GALCEAVA, O.,ALEXANDRU, D.O., GUTA, M.M., GHEORMAN, V., PADUREANU,V., FORTOFOIU, C.M., DIJ MARESCU, A.L., GHEONEA, D.I., Correlation Between Liver Cirrhosis and Risk of Cardiac Arrhythmias, Rev Chim(Bucharest), 69, no 6, 2018, p. 1527-1532.

17.GHEORMAN,V., MILITARU. F, CALBOREAN,V., GHEORMAN, L.M.,CHIRITA, A.L., MITA, A., GALCEAVA, O., GHEORMAN, V., STANCA, D.,UDRISTOIU, I., Clinical and biochemical consideration regarding stress and arrhytmic risk in patients with chronic viral liver diseases, Rev Chim. (Bucharest), 69, no. 4, 2018, p.881-885.

18.PUIU,I., ALBU,C.V., TARTEA,E.A., CALBOREAN,V., GHEORMAN,V., DINESCU,S.N., VASILE,R.C., DINESCU,V.C., BICA, E.C., ROMANESCU, F.M., TUDORASCU,D.R. Relationships Between Glial Enteric Cells, Beta-cell Signaling and Tumor Proliferative Activity in Patients with Colorectal Neoplasia, Rev Chim (Bucharest), 69, no 10, 2018, p. 27442748.

19.BALEANU, V.D., VASILE, D., GOGANAU, A.M., TOMESCU, P.I., DAVITOIU, D., BELEGA, A., GEORGESCU, I., ALEXANDRU, D.O., BORDU, S.I., VOICU, D.I., MANDA, A.L. Clinical and Biochimical Comorbidities and Complications in Abdominal Surgery Using Synthetic Prosthetic Material. Rev.Chim.(Bucharest), 69, no. 6, 2018; p. 1519-23.

20. VLADU, I.M. , RADU, L., GIRGAVU, S.G. , BALEANU, V. , CLENCIU, D. , ENE, C.G. , SOCEA, B., MAZEN, E. , CRISTEA, O.M., MOTA ,M., TENEA COJAN, T.S., An Easy Way to Detect Cardiovascular Risk; Rev.Chim.(Bucharest), 69, no.11, 2018, p. 4229-4232

21.WILLIAMS G, BING C, CAI XJ, HARROLD JA, KING PJ, LIU XH. The hypothalamus and the control of energy homeostasis. Different circuits, different purposes. Physiol Behav 2001; 74:683-701.

22.CALBOREAN,V., GHEORMAN,V., AL NAMAT, R., CAZACU,I. M., VARJU,P., GEDE, N., STREBA,T.C., VERE, C.C., GHEONEA,D.I., GHEORMAN, V., LUNGULESCU, C., LUNGULESCU, C., V. The Association Between Stress Level and Laboratory Parameters, Sex, Age and Stage Disease in Patients with Digestive and Bronchopulmonary Neoplasms, Rev Chim (Bucharest), 68, no 12, 2017, p.3010-3014.

23.BUICU, G.E., GRECU, M.G., SALCUDEAN, A., GRECU, I.G., MARINESCU, C., NIRESTEAN, A., TURLIUC, S., HADAREANU, V., UDRISTOIU, I. Evaluation of elder physical abuse. EUROPEAN PSYCHIATRY, 41, 2017, p S583-S584.

24.CHIMORGIACHIS,A., CONSTANTIN,M.D.G., UDRISTOIU,T., PIRLOG,M.C.,UDRISOIU,I. Weight gain in patients with schizophrenia and atypical antipsychotic treatment - neurobiological correlations. JOURNAL OF NEURAL TRANSMISSION, 114, issue 7, 2007, p. CXXCXX.

25.CALBOREAN, V., GHEORMAN, V., CONSTANTIN, C., ISTRATOAIE, O., J ournal of Cardiovascular Emergencies, 2018, 4, nr.2, p. 101-105. 26.CALBOREAN, V., GHEORMAN, V., DINESCU, N.S., STANCA, D., GALCEAVA,O., FORTOFOIU, M., MITA, A., MIHAILOVICl, A.R., MISCOCl, S.A., BALEANU, V.D., DINESCU,V.C., Arrhythmia risk in patients with chronic hepatic disease. Rev. Chim. (Bucharest), 69, no. 11, 2018, p.4237-4240.

Manuscript received: 21.12 .2018 